Annuaire suisse de politique de développement

18 | 1999

La Suisse et l'action humanitaire

\title{
Evaluating humanitarian action
}

\section{Niels Dabelstein}

\section{OpenEdition}

\section{Journals}

Electronic version

URL: http://journals.openedition.org/aspd/672

DOI: $10.4000 /$ aspd.672

ISSN: 1663-9669

\section{Publisher}

Institut de hautes études internationales et du développement

\section{Printed version}

Date of publication: 1 January 1999

Number of pages: 61-72

ISSN: 1660-5934

\section{Electronic reference}

Niels Dabelstein, «Evaluating humanitarian action », Annuaire suisse de politique de développement [En ligne], 18| 1999, mis en ligne le 12 juillet 2012, consulté le 08 septembre 2020. URL : http:// journals.openedition.org/aspd/672 ; DOI : https://doi.org/10.4000/aspd.672 


\section{EVALUATING HUMANITARIAN ACTION}

Niels Dabelstein*

\section{INTRODUCTION'}

Evaluation of humanitarian action is becoming increasingly important for several reasons:

- The effectiveness of relief operations is crucial to the beneficiaries.

- Humanitarian operations are becoming more complex and more frequent. The number of conflicts requiring humanitarian assistance has increased dramatically, and humanitarian aid's share of overall international aid reached a peak of $10 \%$ in 1994.

- Humanitarian operations are characterised by turbulence, uncertainty, insecurity, political sensitivity and multitudes of beneficiary groups, implementing actors and funding agencies with different interests and agendas. At operational level the focus on immediate needs and tasks detracts attention from broader and long-term perspectives.

- Humanitarian agencies have short institutional memories. Personnel turnover is extremely rapid and the majority of field workers are young and have a relatively short "life time". Hard-learned lessons are not passed on.

\section{CURRENT ISSUES IN EVALUATING HUMANITARIAN ACTION}

Over the past few years several evaluations of humanitarian responses have been conducted by various implementing and funding agencies. While indeed valuable, they mostly focus on a limited field of operation or on the operations of a single agency.

Among bilateral donors the African Food Crisis of the mid-1980s prompted at least two major evaluations: by USAID in 1986 and ODA in 1988. Since then, there have been several more significant studies, for example those by CIDA in 1992, SIDA in 1994 and 1995; ODA, 1990, 1994 and 1995; the Netherlands in 1994 and USAID in 1994. Since its formation in 1992 ECHO has undertaken over 100 project evaluations with a more narrow operational focus. More recently two evaluations of humanitarian programmes in complex emergencies have been undertaken with the encouragement and support of bilateral donors one on Operation Lifeline Sudan (Apthorpe 1996) and one on WFP's operations

* Head of DANIDA's Evaluation Secretariat, Denmark, since 1988. During 1994-1996 he led the Joint Evaluation of the International Response to the Rwanda Genocide. In 1997 he was elected Chairman of the OECD/DAC Working Party on Aid Evaluation.

1. This article draws heavily on the draft "Guidance for Evaluation Managers" which will be published by the DAC Working Party on Aid Evaluation in 1999 and on a report on the findings of a AusAid supported workshop at the National Centre for Development Studies, Australian National University, Canberra, March 1998 (Apthorpe and Neville 1998), in both of which the author of this article has been involved. Thanks are extended to the authors of those papers. 
in support of refugees and displaced persons in Liberia, Sierra Leone, Guinea and Côte d'Ivoire (Karim 1996). The growth in the number of humanitarian aid evaluations undertaken by donor organisations has been mirrored within the UN system and NGOs. Worth mentioning are the UNHCR/UNICEF/WFP evaluation of Operational Co-ordination in the Great Lakes Region during 1996 and the IASC (International Accounting Standards Committee) evaluation of Strategic Co-ordination in the Great Lakes Region during $1996^{2}$. However, many of these studies are not placed in the public domain or, at least, are not readily available.

In 1995-96 the largest and most comprehensive evaluation ever of an emergency programme was undertaken by the DANIDA-led Steering Committee of the Joint Evaluation of Emergency Assistance to Rwanda which assessed the international response to the conflict and genocide (Eriksson et al. 1996).

The Rwanda evaluation was unusual in many ways, two of which stand out:

- it was an evaluation of the entire international community's response to genocide organised jointly by 38 very diverse agencies, and

a the Rwanda genocide and mass movement of refugees was a highly dynamic event in which the international community operated without clearly defined objectives and outcomes.

The evaluation consisted of four studies: Historical Perspective (Sellström and Wohlgemuth 1996), Early Warning and Conflict Management (Adelman and Suhrke 1996), Humanitarian Aid and Effects (Borton et al. 1996), and Rebuilding Post-War Rwanda (Kumar and Tardif-Douglin 1996) and a synthesis (Eriksson et al. 1996). The division of labour between the four study teams was based on the continuum concept: emergency prevention; emergency preparedness and delivery; repatriation, rehabilitation and reconstruction; and the relationship between emergencies, emergency aid and long-term development. The continuum would be covered through a multidimensional approach with the four component studies each covering a dimension of the very complex emergency in Rwanda seen in a regional context.

The Rwanda evaluation was the first joint evaluation of collective operations in a complex emergency. While not necessarily more cost effective than a number of individual evaluations, its value lies in the broad coverage, the comprehensiveness of analyses and thus in the validity of lessons learned. The evaluation was an eye opener - in many respects - also for the aid evaluation profession (Dabelstein 1996).

As more evaluations of humanitarian assistance operations are completed, it has become possible to compare the approaches as well as the results of different studies. Such comparisons reveal remarkable differences in the scope and methods used by the studies, and it would not be a great exaggeration to characterise the current situation as "methodological anarchy". Given the differences in approach, methods and resources, the comparison of the results is highly problematic and from a policy perspective the studies are of limited use beyond the organisations upon which they focused. Given the highly interconnected nature

2. One might wonder why two such closely related evaluations were carried out simultaneously but separately instead of being merged into one comprehensive study. 
of assistance, contributions, and interventions by different organisations and agencies within humanitarian assistance programmes, the inability to compare evaluations is a cause of concern (Borton and Macrae 1998).

An almost universal finding of evaluations of humanitarian assistance has been that the evaluation process was considerably hampered by lack of consistent and comparable data on key aspects of the programmes. The Joint Evaluation of Emergency Assistance to Rwanda (Borton et al. 1996) found that: "The availability and quality of performance data and reporting by official agencies and NGOs ... was highly variable. In some locations ... the availability of data was patchy and frequently not comparable between agencies due to a lack of standardised survey methods and inadequate technical co-ordination. In such areas the information available did not provide a sufficient basis for assessing impact or performance, or ... adjusting programme activities to improve performance" (p. 162).

Similarly the Programme Policy Evaluation of WFP assistance to refugees and displaced persons in Liberia, Sierra Leone, Guinea and Côte d'Ivoire over the period 1990-95 (Apthorpe 1996) stated: "One of the recurring themes of the evaluation is the lack of consistent and reliable data, a failing that has been a major constraint for all aspects of the operation" (p. 9).

Thus, better monitoring and reporting systems are sine qua non to achieving long-term improvement in the evaluation of humanitarian aid, as well as to enhancing the quality of its management by international donors and implementing agencies.

\section{INITIATIVES TO IMPROVE EVALUATION OF HUMANITARIAN ACTION}

The necessity to identify and encourage adoption of best practice in monitoring, reporting, and evaluation of humanitarian response to complex emergencies is recognised by a range of donor organisations and relief agencies, a development considerably assisted by the publication in March 1996 of the Joint Evaluation of Emergency Assistance to Rwanda (Eriksson et al. 1996). Stimulated considerably by this experience a series of meetings were held within a variety of formal and informal policy fora for accountability and performance of humanitarian action. These have included a meeting of the Hexagon Group in May $1996^{3}$ which noted the need to co-ordinate various initiatives on development and application of codes and standards and for donors to develop a common set of monitoring and reporting procedures. Following the Hexagon meeting a joint DANIDA/ODA meeting, known as the Stakis Meeting, in June 1996 agreed to explore the scope to establish an informal network on standards, performance assessment and reporting, and to conduct a mapping exercise documenting existing reporting requirements and evaluation mechanisms.

These initiatives led the Overseas Development Institute (ODI) to develop ALNAP - the Active Learning Network on Accountability and Performance in humanitarian assistance - with support of the UK Overseas Development

3. Comprising Heads of Humanitarian/Emergency Aid Sections of Denmark, Finland, Germany, Ireland, Netherlands, Sweden and the UK with Norway also attending. 
Administration (ODA, now DFID). The principal activities of ALNAP are to collect, periodically synthesise and disseminate the results of evaluations of humanitarian aid programmes; to conduct studies of key topics, to conduct seminars on specific issues of policy importance, and to establish a moderated e-mail discussion.

In addition to the above initiatives, important work has also been done within the UN system, among NGOs and the DAC.

Within the UN, the "Substantive Inter-Agency Working Group on Evaluation and Accountability", chaired by DHA (now OCHA), was formed in early 1996 to consider ways in which the monitoring and evaluation activities of the relevant UN agencies could be better co-ordinated and shared.

The NGO community has developed accountability mechanisms and standards, which included the formulation of the Red Cross/NGO Code of Conduct (SCHR 1994), which is now adopted by more than 150 NGOs. Following this, the Steering Committee for Humanitarian Response (SCHR) and the US NGO umbrella organisation InterAction agreed to jointly develop a Claimants' Charter setting out the entitlement rights of beneficiaries and a set of "industry standards" covering minimum and relative entitlements, modes of delivery of assistance, and accountability of intervening agencies. The project, called Sphere, will present the proposed standards in early 1999.

Finally, the DAC's Working Party on Aid Evaluation, in April 1996, decided to prepare a compendium of best practices for monitoring and evaluation approaches and methodologies ${ }^{4}$, to identify key indicators and set standards for data collection and reporting as a way of facilitating assessment of overall effectiveness and impact of programmes, and to encourage collaborative evaluations.

All these initiatives took place and are pursued within established fora: the donor community, the NGO community and the UN family, and although there is a considerable degree of exchange of information and some co-ordination, there is a risk that the resulting charters, standards, procedures and best practices will be "owned" primarily by the initiating forum, and not be fully accepted and adopted by other fora.

One particular initiative attempts to overcome this limitation. After publication in 1996 of the Rwanda Evaluation, a one year follow-up process (Joint Evaluation Follow-up and Facilitation JEFF) was established to track and report on the evaluation's impact. This follow-up process revealed a gap in the international community's capacity to monitor, analyse, discuss objectively and facilitate the kind of responses, policies, and reforms that are necessary to more effectively prevent and mitigate the impact of violent conflict. This global level gap cannot be filled by the UN, NGOs or bilaterals alone; most of their structures and mandates were created in and for another time; and their current involvement in complex emergencies could present real or perceived conflicts of interest. Finally, most existing structures tend to be defined by limited purposes and participation, e.g., humanitarian, developmental, political, or military, etc. (JEFF 1997).

4. This work will produce two separate papers: a "Guidance for Evaluation Managers" to be published by the DAC and a "Good Practice Review" published by ODI's Relief and Rehabilitation Network (Hallam 1998). 
In early 1997, a small group of individuals from the governmental and non-governmental sectors ${ }^{5}$ who had been involved in the evaluation and its follow-up began to discuss how to create a forum and an international mechanism to improve the way in which the international community could deal with this gap. The group set up a process of consultation with a broad range of bilateral, multilateral, and non-governmental organisations in developed and developing countries. These consultations led to a proposal to create a "capacity" with an "International Council" to analyse, monitor and report on the collective ability of the international system to deal with potential and actual violent conflict ${ }^{6}$. An important aspect of the "International Council" would be to get the diverse group of actors out of their development, political, or humanitarian boxes to jointly search for and advocate solutions.

The "Council" should be inclusive, encompassing those institutions who play important roles in conflict prone and ridden areas, e.g. not only governments, multilateral and private voluntary organisations, but also multinational corporations and the media. It should include representatives from developing as well as developed countries. The "Council's" mandate should cover political and development factors and assistance in pre- and post- conflict periods and humanitarian assistance. Such a "Council" cannot be truly independent, but it will derive its strength from its collaborative and multi-dependent character similar to that of the Steering Committee for the Joint Evaluation of Emergency Assistance to Rwanda. Although there is a general acceptance of the need for such a body, concrete steps to establish it have yet to be taken.

\section{WHY IS EVALUATION OF HUMANITARIAN ACTION DIFFERENT}

There are many ways in which the evaluation of humanitarian action in complex emergencies is little different from evaluation of development aid in general: Terms of Reference need to be prepared, teams selected, field study undertaken and reports and recommendations prepared. However, the very characteristics of complex emergencies, the political and military context, and the way international assistance is organised and provided require the explicit consideration of, and in many instances an emphasis upon, approaches to evaluation which are not typical of those used in development aid.

\section{$\square$ How to Evaluate}

\section{Reconstructing the History}

A result of the characteristics of complex emergencies is that key information on a range of matters of vital significance to evaluators is often unavailable. Whilst evaluators of development assistance are also often faced with lack of information on key indicators or decisions, such problems are considerably and routinely more serious in evaluations of humanitarian assistance in complex emergencies. The multiplicity of actors, the fluidity of the situation, the difficulties of working in the context of war and instability, the frequent absence of

5. DANIDA, IFRC, ODI, OXFAM, SIDA, USAID

6. "International Council to Analyze, Monitor, Report on and Facilitate Progress in Addressing the Phenomenon of Complex Emergencies", unpublished draft, April 1998. 
baseline data on the condition of the affected/target populations prior to the assistance intervention, the failure by some agencies to monitor key indicators, the lack of agreement on standardised monitoring procedures and protocols among agencies, and the difficulties of adhering to normal standards for recording discussions and decisions and maintaining filing systems, all combine to produce a situation where information which is vital to evaluators either does not exist or is not easily accessible. Thus, evaluators of responses to complex emergencies are routinely faced not only with the need to compensate for missing data, but also to contend with a lack of information on the context, the precise sequence of events during the period and the goals and (often changing) policies of different actors at different stages of the emergency. In other words they have to reconstruct "histories" and "pictures" of the events to serve as a form of baseline from which to judge the appropriateness and effectiveness of the policies and interventions.

"Total system" evaluations will almost always require a substantial degree of "baseline" construction, to fit alongside evaluations of response policies and selected illustrative projects. However, evaluations of single projects - even comparatively "technical" projects - do not escape the need to construct such baselines. The evaluation of a project by Agency B to establish treatment centres for dysentery cases or a project by Agency $\mathrm{C}$ to establish water production and distribution systems for displaced populations will require context setting, explanation of the events in the project area, assessment of the needs that the projects were attempting to address, and illustration of the relationship between the projects undertaken and those undertaken in the same area by other agencies. Such explanation may reveal that alternative actions by the agencies or other actors earlier in the emergency might have prevented the dysentery outbreak or avoided the population being displaced. More effective action earlier by agencies $\mathrm{B}$ and $\mathrm{C}$ or by other agencies and actors might have avoided the need for subsequent interventions.

\section{Policy Evaluation}

The construction of narrative histories, as discussed above, is just one of the tools commonly used by those undertaking "policy evaluation". The approaches and techniques of policy evaluation are likely to be particularly helpful to evaluators explaining and analysing policies in relation to complex emergencies regardless of the scope and nature of an intervention - and are considered briefly below

Explanation based on the separation of cause from effect is often not possible when looking at a complex system composed of numerous interdependent relationships; it may not be possible to separate cause and effect because the direction of influence is often circular rather than linear. Thus methods which are more common in historical or philosophical research are often more productive than those traditionally employed in the social sciences. Such methods acknowledge the complexity and interdependent nature of events in the real world and ask not, "did X cause Y?" but rather, "what happened?" and "why?". In other words, in order to understand and be able to deal with situations and structures, they seek to build narratives about specific events and processes, rather than theorising grandly and establishing causal relationships. 
Evaluation has much to gain by borrowing from these historical and philosophical methods. The first step in using this approach to analyse a particular set of events and processes is to construct a narrative history to serve as a kind of model or spectrum through which to view what is to be understood and explained. A range of different actors may be asked to tell their story, recognising that what they say represents the truth as they see it or the truth, as they would like the evaluator to see it. In this way a partial understanding of someone else's view of reality may be developed. The stories of many different actors are then added to the available documentary evidence to construct the narrative history. The narrative history is therefore more than a simple chronology. It details not just what happened and when, but also who was involved, and links significant events. For an evaluator, this narrative history establishes a baseline, or template, which helps to make judgements about events and processes.

The evaluator then has to go beyond this baseline, or template, and explain why actors did what they did and with what effects. In other words, filter the narrative (raw data) through some sort of analytical framework and draw practical conclusions accordingly. The framework may arise out of the stories themselves. When many different stories are accumulated, consistent patterns may emerge. Alternatively, the framework may arise out of previous studies and be confirmed by the evidence revealed in the narrative history.

At the same time, it must be remembered that consultancy is not research, nor research consultancy: each has its own standards and practices. Currently, most evaluations of humanitarian aid are done through consultancies. The main exception to this general rule is the Rwanda Joint Evaluation. In this case, the level of resources and time committed was such that the research/consultancy line was significantly blurred.

The narrative history approach described above is particularly suited to evaluating complex emergencies because it relies on qualitative rather than quantitative data; because it allows the evaluator to focus on actions and intentions; and because it highlights the competing agendas of the diverse range of actors. Furthermore, use of the narrative history approach does not preclude the use of more analytical models, such as logical frameworks or cost-effectiveness reviews, to examine specific components of an emergency assistance program.

\section{Working in Areas of Conflict and Instability}

The nature of the matter requires that evaluations of responses to complex emergencies be undertaken in areas that have recently experienced active conflict and may continue to experience instability and insecurity. Whilst it is rare for evaluation teams to be deployed to areas of active conflict, this is not unknown. Whether an evaluation takes place during active conflict or shortly after, the context of conflict and instability affects the work of the evaluation team. Probably the most important factors are the impact of the events upon those being interviewed and the extreme sensitivity of the issues.

Regardless of who the team is interviewing, be it government officials or a "rebel" faction, relief workers, military personnel within the factions and in peacekeeping contingents, or the affected civilian population who received assistance, it is important that the team bears in mind, and as far as possible 
empathises with, the experiences that the interviewees have endured. The affected population will have just experienced a civil war during which they may have been forcibly displaced, had relatives and friends killed, either in the fighting or during atrocities committed against civilians, and seen their personal, social and perhaps cultural identities shattered. Psycho-social trauma may affect much larger numbers than is evident to an outsider, particularly if unfamiliar with the local language and untrained in the diagnosis of post-traumatic stress disorders. Exposed to such extreme experiences and perhaps having themselves witnessed massacre sites, it is not unheard of for members of evaluation teams to also experience mild forms of traumatic stress disorders.

Civil wars greatly exacerbate and deepen fault lines within a society and may well create new cleavages in previously coherent groups (e.g. between those who stayed through the conflict and those who sought safety outside the country; those who came to support a new faction and those who remained loyal to a former government or faction). Such is the intensity of feeling and the polarisation of affected societies that objectivity and the truth become difficult concepts to uphold. It is not uncommon for evaluators working in complex emergencies to experience two intelligent and articulate adults giving completely contradictory versions of the same event. In such situations evaluators may have to accept that their search for "the truth" may never be successful. The implication of this for their work is that the veracity of information collected cannot be taken for granted and will require constant checking and cross-checking.

\section{$\square$ What to Evaluate}

OECD/DAC's definition of evaluation as "an examination, as systematic and objective as possible, of an on-going or completed project or programme, its design, implementation and results, with the aim of determining its efficiency, effectiveness, impact, sustainability and the relevance of its objectives" has become the standard for evaluating development programmes. While these evaluation criteria are broadly appropriate for humanitarian assistance programmes, their usefulness may be enhanced by expanding the meaning of these criteria and by adding sub-criteria, such as "coverage", "coherence" and "connectedness". These complementary sub-criteria are discussed below.

Efficiency measures the outputs - qualitative and quantitative - in relation to the inputs. This generally requires comparing alternative approaches to achieving the same outputs, to see whether the most efficient process has been used.

Effectiveness measures the extent to which the activity achieves its purpose, or whether this can be expected to happen on the basis of the outputs. Implicit within the criteria of effectiveness is timeliness (for if the delivery of food assistance is significantly delayed the nutritional status of the target population will decline). There is value in using it more explicitly as one of the standard criteria because of its importance in the assessment of emergency programmes. Similarly, issues of resourcing and preparedness should be addressed

Impact looks at the wider effects of the project - social, economic, technical, environmental - on individuals, communities, and institutions. Impacts can be

7. This section draws extensively on "Good Practice Review - Evaluating Humanitarian Assistance Programmes in Complex Emergencies" referred to in footnote 4. 
immediate and long-range, intended and unintended, positive and negative, macro (sector) and micro (household). Impact studies address the question: what real difference has the activity made to the beneficiaries? How many have been affected?

Relevance is concerned with assessing whether the project is in line with local needs and priorities (as well as with donor policy). A recent evaluation of humanitarian assistance replaced the criteria of relevance with the criteria of appropriateness - the need "to tailor humanitarian activities to local needs, increasing ownership, accountability, and cost-effectiveness accordingly" (Minear 1994). However, the two criteria complement rather than substitute each other. "Relevance" refers to the overall goal and purpose of a programme, whereas "appropriateness" is more focused on the activities and inputs. The addition of the new criteria drew attention to the fact that even where the overall programme goal is relevant - for example, to improve nutritional status - there are still questions to be asked about the programme purpose. Distributing large quantities of food aid may not be the best way of improving nutritional status. Alternatives could include food for work, cash for work, or measures to improve the functioning of local markets. Furthermore, even if distribution of food aid is deemed appropriate, it is still necessary to examine the appropriateness of the food that is distributed.

Sustainability - of particular importance for development aid - is concerned with measuring whether an activity or an impact is likely to continue after donor funding has been withdrawn. Projects need to be environmentally as well as financially sustainable. However, many humanitarian interventions, in contrast to development projects, are not designed to be sustainable. They still need assessing, however, in regard to whether, in responding to acute and immediate needs, they take the longer-term into account. Larry Minear has referred to this as connectedness, the need "to assure that activities of a short-term emergency nature are carried out in a context which takes longer-term and interconnected problems into account" (Minear 1994). For example, otherwise efficient food distribution programmes can damage roads used by local traders, while the presence of large refugee camps can result in severe environmental impacts in neighbouring areas. Local institutions can also suffer - the high salaries paid by international NGOs can attract skilled staff away from government clinics and schools, leaving the local population with reduced levels of service. Large-scale relief programmes can also have a significant impact on local power structures, for better or for worse.

Coverage - the need "to reach major population groups facing life-threatening suffering wherever they are, providing them with assistance and protection proportionate to their need and devoid of extraneous political agendas" (Minear, 1994) - alerts evaluators that complex emergencies and associated humanitarian programmes can have significantly differing impacts on different population sub-groups, whether these are defined in terms of ethnicity, gender, socio-economic status, occupation, location (urban/rural or inside/outside of a country affected by conflict) or family circumstance (e.g. single mother, orphan). Programmes need to be assessed both in terms of which groups are included in a programme, and the differential impact on those included. For example, studies have shown that, in Ethiopia in the 1980s, more than $90 \%$ of international relief 
went to government-controlled areas, penalising those in areas of Tigray and Eritrea controlled by insurgent movements (Minear 1994). Other studies have revealed that single mothers may be disadvantaged when it comes to access to resources, as they are unable to leave children to queue for relief goods. In the case of the Great Lakes emergency, it was found that the coverage of the response varied enormously: refugees and IDPs, and residents in neighbouring IDP camps, were often treated in quite different ways, despite having very similar needs (Borton et al. 1996)

Coherence - refers to policy coherence, and the need to assess security, developmental, trade and military policies as well as humanitarian policies, to ensure that there is consistency and, in particular, that all policies take into account humanitarian and human rights considerations.

A notable lack of coherence was evident in the international community's response to the Great Lakes emergency in 1994. During the crisis military contingents were withdrawn from Rwanda during the genocide, when there is evidence to suggest that a rapid deployment of troops could have prevented many of the killings and the subsequent refugee influx into Zaire. This was then followed by a huge relief operation.

In other instances, donor-imposed trade conditions have been blamed for precipitating economic crisis and conflict, undermining longer-term development policies. Coherence can also be analysed solely within the humanitarian sphere - to see whether all the actors are working towards the same basic goals. For example, there have been instances of one major UN agency promoting the return of refugees to their host country while another is diametrically opposed to such policies.

Finally, it is also important to assess whether agencies are taking into account the safety of their own staff, not only from violence, but also from sickness and disease. For example, staff should not be expected to work for long periods in highly volatile areas - where their personal safety may be in doubt - without adequate support.

Finally, there is the important issue of co-ordination. This could be considered under the criteria of effectiveness, for a poorly co-ordinated response is unlikely to maximise effectiveness or impact. However, given the multiplicity of actors involved in an emergency response, it is important that co-ordination is explicitly considered - the intervention of a single agency cannot be evaluated in isolation from what others are doing, particularly as what may seem appropriate from the point of view of a single actor, may not be appropriate from the point of view of the system as a whole.

\section{CONCLUSION}

While individual organisations' evaluations of their own activities may address all or most of the above issues, they will tend to focus on a limited field of operation. Other activities may only be treated as context, not as complementary and inter-linked, often overlapping and sometimes conflicting. Agency specific evaluations will more often than not evaluate implementation of policies rather 
than the relevance and applicability of those policies and the assumptions behind them.

The Joint Evaluation of Emergency Assistance to Rwanda showed the synergetic effect of many agencies co-operating, thereby amplifying the power of lessons. It documented that multi-agency, joint, overall evaluations will yield generally applicable lessons for the political, military and humanitarian systems and can focus policy discussions and achieve an impetus that is simply out of reach of any number of smaller, partial coverage studies. Joint evaluations should become a regular feature of the humanitarian system if the system is to keep learning and improving effectively.

The Rwanda evaluation was not initiated by the "system" but by a single agency. It is by no means certain that a similar initiative will succeed in the future. None of the existing international bodies represent the entire humanitarian aid community - or the beneficiaries. There is a need to identify or establish an independent international unit responsible for monitoring and evaluating the totality of emergency response and humanitarian assistance. It might be worth looking at the evaluation system set up for the Global Environmental Fund or to revisit the proposed "International Capacity".

\section{Acronyms}

$\begin{array}{ll}\text { ALNAP } & \text { Active Learning Network } \\ & \text { on Accountability and Performance in Humanitarian Assistance } \\ \text { CIDA } & \text { Canadian International Development Agency } \\ \text { DAC } & \text { Development Assistance Committee (of the OECD) } \\ \text { DANIDA } & \text { Danish International Development Assistance } \\ \text { DFID } & \text { Department for International Development (UK) } \\ \text { DHA } & \text { UN Department for Humanitarian Affairs } \\ \text { ECHO } & \text { European Commission Humanitarian Office } \\ \text { IASC } & \text { International Accounting Standards Committee } \\ \text { ICRC } & \text { International Committee of the Red Cross and Red Crescent } \\ \text { IDP } & \text { Internally Displaced Person } \\ \text { IFRC } & \text { International Federation of Red Cross and Red Crescent } \\ \text { JEFF } & \text { Joint Evaluation Follow-up Monitoring and Facilitation Network } \\ \text { NGO } & \text { Non-Governmental Organisation } \\ & \text { US: Private Voluntary Organisation) } \\ \text { OCHA } & \text { UN Office for the Coordination of Humanitarian Affairs } \\ \text { ODA } & \text { Overseas Development Administration (now DFID) } \\ \text { ODI } & \text { Overseas Development Institute } \\ \text { OECD } & \text { Organisation for Economic Cooperation and Development } \\ \text { SCHR } & \text { Steering Committee for Humanitarian Response (NGOs) } \\ \text { SIDA } & \text { Swedish International Development Agency } \\ \text { UN } & \text { United Nations } \\ \text { UNHCR } & \text { UN High Commissioner for Refugees } \\ \text { UNICEF } & \text { United Nations International Children's Emergency Fund } \\ \text { USAID } & \text { United States Agency for International Development } \\ \text { WFP } & \text { World Food Programme } \\ \end{array}$




\section{REFERENCES}

Adelman, H. and Suhrke, A. 1996: Early Warning and Conflict Prevention, Study II of The International Response to Conflict and Genocide: Lessons from the Rwanda Experience, Danida: Copenhagen.

Apthorpe, R. 1996: Protracted Emergency Humanitarian Relief Food Aid: Towards Productive Relief, Programme Policy Evaluation of the 1990-95 period of WFP-assisted refugees and displaced persons operations in Liberia, Sierra Leone and Côte d'lvoire, WFP: Rome.

Apthorpe, R. and Neville, A. 1998: Managing Emergency Humanitarian Aid Evaluation: Lessons from Experience, a report from a workshop held with AusAid support at the National Centre for Development Studies, Australian National University: Canberra.

Borton, J. and Macrae, J. 1998: Evaluation Synthesis of Emergency Aid, EV 613 Department for International Development: London.

Borton, J., Brusset, E. and Hallam A. 1996: Humanitarian Aid and Effects, Study III of The International Response to Conflict and Genocide: Lessons from the Rwanda Experience, DANIDA: Copenhagen.

Dabelstein, N. 1996: Evaluating the International Humanitarian System, Disasters, vol. 20 no. 4, ODI: London.

Eriksson, J. et al. 1996: The International Response to Conflict and Genocide: Lessons from the Rwanda Experience, Danida: Copenhagen.

Hallam, A. 1998: "Evaluating Humanitarian Assistance Programmes in Complex Emergencies", RRN Good Practice Review no. 7, ODI: London.

JEFF - Joint Evaluation Follow-up Monitoring and Facilitation Network, 1997: The Joint Evaluation of Emergency Assistance to Rwanda: A Review of Follow-up and Impact Fifteen Months After Publication, SIDA: Stockholm, ODA: London.

Karim, A. et al. 1996: Operation Lifeline Sudan: A Review, DHA: Geneva, UNICEF: New York.

Kirkby, J., Kliest, T. and O'Keefe, P. 1997: The Complex Emergency in Somalia: UNHCR's Cross Border Cross Mandate Operation, Netherlands Ministry of Foreign Affairs: The Hague.

Kumar, K. and Tardif-Douglin, 1996: Rebuilding Post-Genocide Rwanda, Study IV of The International Response to Conflict and Genocide: Lessons from the Rwanda Experience, DANIDA: Copenhagen.

Minear, L. 1994: The International Relief System: A Critical Review, Paper presented to the Parallel National Intelligence Estimate on Global Humanitarian Emergencies, Meridian International Centre, Washington D.C. Available from Thomas J. Watson Jr. Institute for International Studies (http://www.brown.edu).

OECD 1992: DAC Principles for Effective Aid, OECD: Paris.

OECD/DAC Working Party on Aid Evaluation: Guidance for Evaluation Managers in Evaluation of Humanitarian Response to Complex Emergencies, OECD: Paris (forthcoming).

Sellström, T. and Wohlgemuth, L. 1996: Historical Perspective: Some Explanatory Factors, Study I of The International Response to Conflict and Genocide: Lessons from the Rwanda Experience, DANIDA: Copenhagen.

SCHR - Steering Committee for Humanitarian Response, 1994: "Code of Conduct for the International Red Cross and Red Crescent Movement and NGOs in Disaster Relief", Relief and Rehabilitation Network Paper no. 4, ODI: London. 